Document downloaded from:

http://hdl.handle.net/10251/96942

This paper must be cited as:

Vayá Pérez, I.; Bueno Alejo, CJ.; Jiménez Molero, MC.; Miranda Alonso, MÁ. (2008).

Determination of enantiomeric compositions by transient absorption spectroscopy using proteins as chiral selectors. Chemistry - A European Journal. 14(36):11284-11287. doi:10.1002/chem.200801657

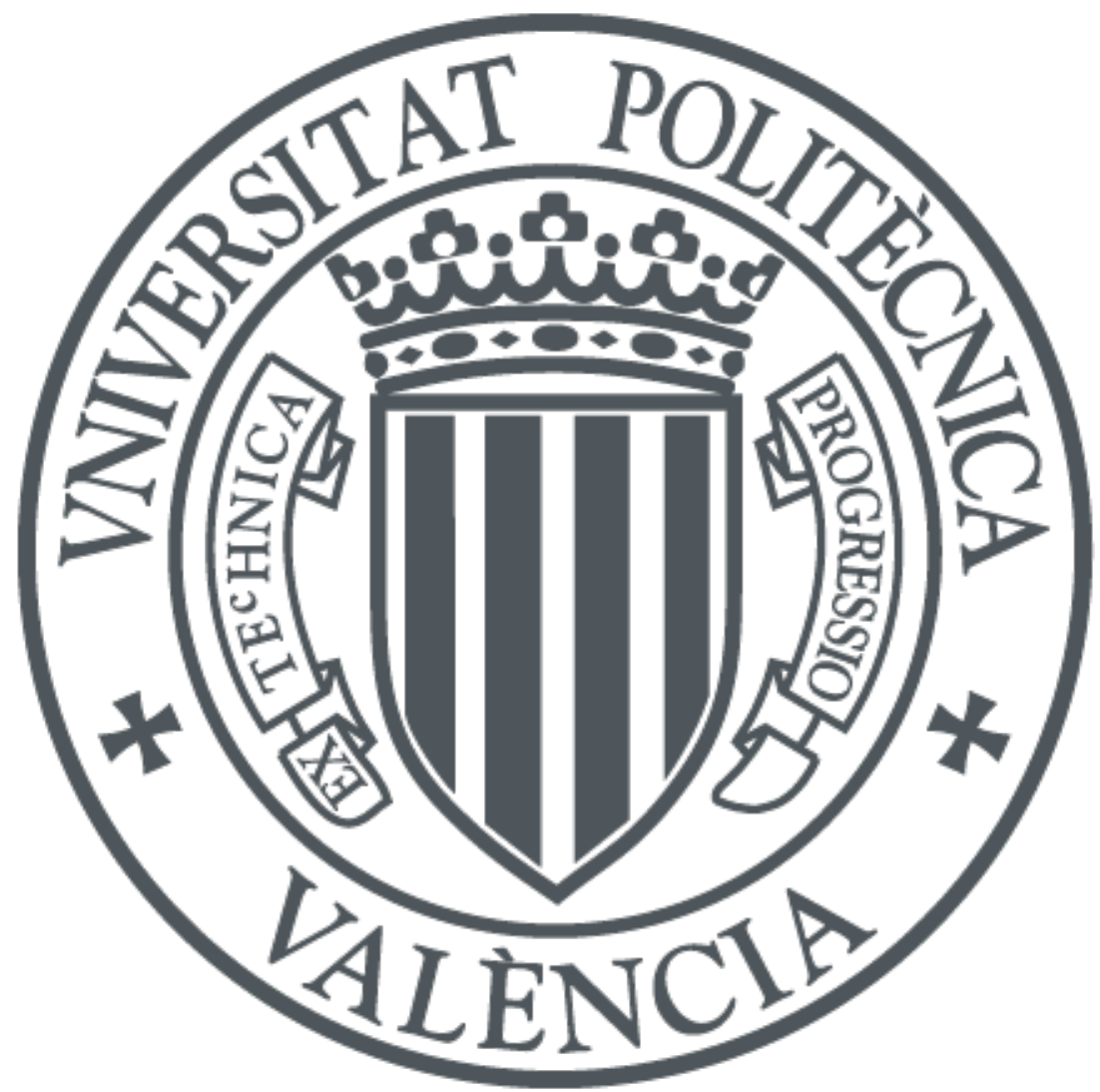

The final publication is available at

https://doi.org/10.1002/chem.200801657

Copyright John Wiley \& Sons

Additional Information 


\title{
Determination of Enantiomeric Compositions by Transient Absorption Spectroscopy using Proteins as Chiral Selectors
}

\author{
Ignacio Vayá, ${ }^{[b]}$ Carlos J. Bueno, ${ }^{[b]}$ M. Consuelo Jiménez ${ }^{*[a, b]}$ and Miguel A. Miranda*[a,b]
}

Determination of the enantiomeric composition is a relevant issue in different areas, including the synthesis of enantiopure chemicals and biologically active substances. ${ }^{[1]}$ In pharmacology, the enantiomers exhibit different behavior in terms of activity, sideeffects, toxicity, metabolism or transport mechanism. Therefore, the development of analytical methods to assess the enantiomeric composition of chiral drugs is of great interest. ${ }^{[2]}$

Direct determination of the enantiomeric excess (ee) can be achieved by polarimetry; ${ }^{[1]}$ however, this technique presents some practical limitations, mainly related to sensitivity and low tolerance to impurities. Other commonly used analytical methods are based on GC and HPLC on chiral stationary phases; their main disadvantages are that they are time-consuming and require serial analysis, which limits the number of samples that can be studied. ${ }^{[3]}$ Other methods have been developed in the last decades, ${ }^{[4]}$ based on the determination of different properties; they include MS, ${ }^{[5]} \mathrm{UV}$-Vis absorption spectroscopy, ${ }^{[6]}$ IR thermography, ${ }^{[7]}$ circular dichroism, ${ }^{[8]}$ capillary electrophoresis, ${ }^{[9]}$ NMR spectroscopy, ${ }^{[10]}$ fluorescence spectroscopy, ${ }^{[11]}$ biochemical assays, ${ }^{[12]}$ etc. In spite of this effort, quantification of stereoisomer levels continues to be an important problem, and therefore further research is still required to develop new analytical methodologies.

In principle, discrimination between enantiomers is possible making use of supramolecular host-guest interactions. In this context, useful information has been obtained by chemometric

[a] Dr. M. C. Jiménez, Prof. M. A. Miranda

Departamento de Química- Instituto de Tecnología Química UPV-CSIC Universidad Politécnica de Valencia

Camino de Vera s/n, Apdo 46022, Valencia, Spain

Fax: $(+) 34963877344$

E-mail: mcjimene@qim.upv.es; mmiranda@qim.upv.es

[b] Dr. I. Vayá, C. J. Bueno, Dr. M. C. Jiménez, Prof. M. A. Miranda

Departamento de Química- Instituto de Tecnología Química UPV-CSIC

Universidad Politécnica de Valencia

Camino de Vera s/n, Apdo 46022, Valencia, Spain

Supporting information for this article is available on the WWW

under http://www.chemeurj.org or from the author. analysis of the UV-Vis absorption or fluorescence spectra in the presence of cyclodextrins. ${ }^{[13]}$ Proteins are another important class of chiral selectors. Particularly, serum albumins (SA) have been widely used as stationary phases for the chromatographic resolution of enantiomeric mixtures, ${ }^{[14]}$ a concept based on the possible stereoselectivity of the binding process.

Recently, we have explored the suitability of triplet excited states as reporters for the binding of drugs to transport proteins, ${ }^{[15]}$ as the properties of these states are very sensitive to the experienced microenvironment. ${ }^{[16]}$ Thus, laser flash photolysis (LFP) measurements have been performed on $(S)$ - and $(R)$-flurbiprofen methyl esters (FBPMe) in the presence of human serum albumin (HSA). Actually, FBPMe is a prodrug of the nonsteroidal antiinflammatory drug flurbiprofen (FBP). In the absence of protein, after LFP at $266 \mathrm{~nm}\left(2.5 \times 10^{-5} \mathrm{M}\right.$, PBS, air), (S)-FBPMe exhibits a characteristic transient triplet-triplet absorption spectrum centered at $360 \mathrm{~nm},{ }^{[17]}$ with a lifetime $\left(\tau_{\mathrm{T}}\right)$ of $1.5 \mu \mathrm{s}$. However, in the presence of $2.5 \times 10^{-5} \mathrm{M}$ HSA, two $\tau_{\mathrm{T}}$ values are observed (31.5 and 4.1 $\mu \mathrm{s}) ;{ }^{[15 a]}$ they have been assigned to $(S)$-FBPMe inside the two well known HSA binding sites (named site I and site II by Sudlow). ${ }^{[18]}$ From the relative contributions of the different $\tau_{\mathrm{T}}$ values at various (S)-FBPMe/HSA ratios, it has been possible to determine the drug distribution among the bulk solution and the protein binding sites. The same trend, but with remarkably different triplet lifetimes (157.6 $\mu \mathrm{s}$ and $16.6 \mu \mathrm{s})$, has been observed for $(R)$-FBPMe/HSA systems. ${ }^{[15 a]}$ For both $(S)$ - and $(R)$-FBPMe, the major (longer-lived) component under non-saturating conditions was assigned to FBPMe within site I, and the minor (shorter-lived) component corresponded to site II-bound FBPMe.

With this background, we decided to make use of the chiral discrimination between the triplet lifetimes of $(S)$ - and $(R)$ - isomers in the supramolecular binding to SA for the development of a new methodology aimed at a rapid and reliable assessment of enantiomeric composition. The strategy is based on the determination of the percentage of both enantiomers from the relative contributions of the triplet lifetimes obtained from the decay curves in the presence of SA as chiral selector (Scheme 1).

As HSA, most of the serum albumins have two high affinity

binding sites for small organic compounds, although this is not necessarily the case for all species. ${ }^{[19]}$ 


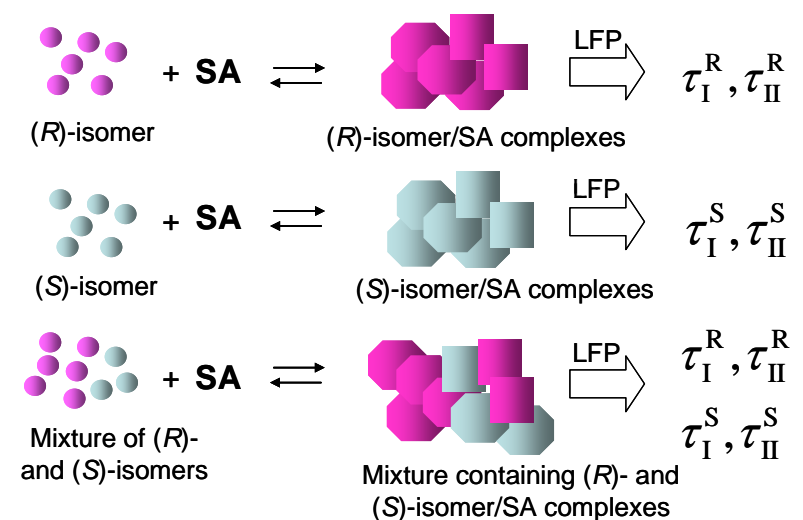

Scheme 1

To prove the concept, a series of solutions containing (S)-and (R)-FBPMe (percentages from 0:100 to 100:0) in the presence of equimolar amounts of HSA were prepared and submitted to LFP. Some of the decays obtained are shown in Figure 1A
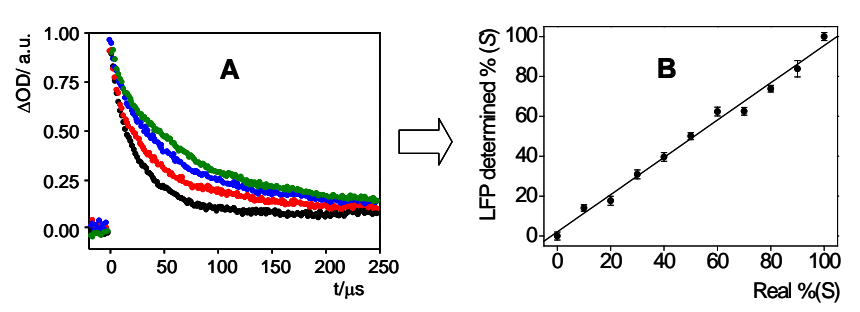

Figure 1. A. Decays $(\lambda=360 \mathrm{~nm})$ for several $(S)$-FBPMe/(R)-FBPMe/HSA mixtures: $1 / 0 / 1$ (black), 0.7/0.3/1 (red), 0.3/0.7/1 (blue) and 0/1/1 (green) after LFP at $266 \mathrm{~nm}$. B. LFP-determined against known real values, together with the linear fit of the experimental points.

It can be clearly seen that, as expected, the decay trace lengthens with increasing amounts of $(R)$-FBPMe. To obtain accurate fittings, it was assumed that, in a given FBPMe/HSA mixture containing both FBPMe enantiomers, four different kinds of triplets are present: they are ascribed to (R)- and (S)- FBPMe, within site I and site II. Then, the multiexponential law for fitting the decay trace would be given by [Eq. (1)]

$\Delta O D=\Delta O D_{0}+A_{1}^{S} e^{\left(-t / \tau_{1}^{S}\right)}+A_{\|}^{S} e^{\left(-t / \tau_{1}^{S}\right)}+A_{1}^{R} e^{\left(-t / \tau_{1}^{R}\right)}+A_{\|}^{R} e^{\left(-t / \tau_{\| 1}^{R}\right)}$

where $\tau_{\mathrm{I}}^{\mathrm{S}}$ and $\tau_{\mathrm{II}} \mathrm{S}$ are the triplet lifetimes of (S)-FBPMe in site I and site II of HSA, whereas $\tau_{I}{ }^{R}$ and $\tau_{I_{I}}{ }^{R}$ are the corresponding values for the (R)-enantiomer. Assuming that the ratios $\mathrm{A}_{\mathrm{I}} \mathrm{S} / \mathrm{A}_{I I} \mathrm{~S}$ and $\mathrm{A}_{\mathrm{I}} \mathrm{R} / \mathrm{A}_{\mathrm{II}} \mathrm{R}$ remain constant (70/30 and 68/32, respectively), ${ }^{[15 a]}$ the fitting of each decay trace allowed us to obtain $A_{I}{ }^{S}$ and $A_{I}{ }^{R}$ and hence the percentage of each FBPMe enantiomer. A plot of the LFPdetermined against known real values is given in Figure $1 \mathrm{~B}$ and clearly validates the proposed methodology.

Similar results were obtained with porcine serum albumin (PSA), although in this case the key parameters were somewhat different $\left(\tau_{\mathrm{I}}^{\mathrm{S}}=41.2 \mu \mathrm{s}, \tau_{\mathrm{I}}^{\mathrm{S}}=6.0 \mu \mathrm{s}, \tau_{\mathrm{I}}^{\mathrm{R}}=95.3 \mu \mathrm{s}, \tau_{\mathrm{II}^{\mathrm{R}}}^{\mathrm{R}}=9.5 \mu \mathrm{s}\right.$, $\mathrm{A}_{I}^{\mathrm{S}} / \mathrm{A}_{I I}{ }^{\mathrm{S}}=53 / 47$ and $\left.\mathrm{A}_{I}^{\mathrm{R}} / \mathrm{A}_{I I}{ }^{\mathrm{R}}=75 / 25\right)$. Selected decays and the linear plot of LFP-determined versus real enantiomeric composition for FBPMe/PSA systems are shown in Figure 2.
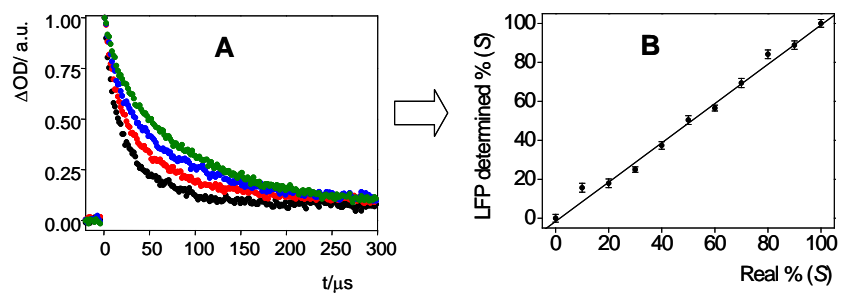

Figure 2. A. Decays $(\lambda=360 \mathrm{~nm})$ for several (S)-FBPMe/(R)-FBPMe/PSA mixtures: 1/0/1 (black), 0.8/0.2/1 (red), 0.4/0.6/1 (blue) and 0/1/1 (green) after LFP at $266 \mathrm{~nm}$. B. LFP-determined against known real values, together with the linear fit of the experimental points.

Although FBPMe should in principle have a small affinity to SAs, its poor hydrophilicity could favor inclusion within the proteins. Preference for site I can be attributed to the type of predominating interactions (hydrophobic and van der Waals).

Chiral discrimination in the triplet lifetimes of the drug-SA complexes is the only requirement for the successful application of this LFP-based methodology, which may not be fulfilled in a number of systems. For example, the triplet lifetimes of the parent drug FBP in the presence of HSA $\left(\tau_{\mathrm{I}}^{\mathrm{S}}=11.2 \mu \mathrm{s}, \tau_{\mathrm{II}}^{\mathrm{S}}=35.9 \mu \mathrm{s}, \tau_{\mathrm{I}}^{\mathrm{R}}=\right.$ $10.2 \mu \mathrm{s}$ and $\left.\tau_{\mathrm{II}}^{\mathrm{R}}=39 \mu \mathrm{s}\right)^{[15 \mathrm{~b}]}$ or PSA $\left(\tau_{\mathrm{I}}^{\mathrm{S}}=6.5 \mu \mathrm{s}, \tau_{\mathrm{II}^{\mathrm{S}}}^{\mathrm{S}}=44.5 \mu \mathrm{s}, \tau_{\mathrm{I}}^{\mathrm{R}}\right.$ $=6.8 \mu \mathrm{s}$ and $\tau_{\mathrm{II}}{ }^{\mathrm{R}}=45.0 \mu \mathrm{s}$ ) are too close, and hence the obtained values for the percentages of the two enantiomers are not reliable. Even in such a case, the problem can be circumvented by choosing a protein where the triplet lifetimes of the two enantiomers are different enough. For FBP, bovine serum albumin (BSA) provides an appropriate chiral selector. Within this protein, a clear stereodifferentiation is indeed observed for (S)- and (R)-FBP within the binding sites $\left(\tau_{\mathrm{I}}^{\mathrm{S}}=10.8 \mu \mathrm{s}, \tau_{\mathrm{II}}^{\mathrm{S}}=86.5 \mu \mathrm{s}, \tau_{\mathrm{I}}^{\mathrm{R}}=6.6 \mu \mathrm{s}\right.$ and $\tau_{\mathrm{II}}{ }^{\mathrm{R}}=$ $58.6 \mu \mathrm{s})^{[15 b]}$ As a matter of fact, when the decay traces obtained in the presence of BSA for different $(S)$-FBP/(R)-FBP ratios were processed in the usual way, good correlations were found between the LFP determined and the real enantiomeric compositions (see Figure S7 in the Supporting Information).

Stereodifferentiation in the triplet excited state interactions between chiral analytes and proteins should in principle be a common phenomenon; a further example (naproxen/HSA) is shown in the Supporting Information (Figure S8). Furthermore, the tolerance of this approach to the presence of impurities was nicely demonstrated by using commercial Froben ${ }^{\circledR}$ tablets, where the content of active principle (racemic FBP) is about $25 \%$; the results are shown in Figures S9-S11. For comparison, the application of polarimetry, NMR and HPLC-based analysis to the case of FBP is given in the Supporting Information (Table 3 and Figures S12 and S13).

In conclusion, a novel method for the straightforward determination of enantiomeric compositions is presented here. It is based on transient spectroscopy, exploiting the differences in triplet lifetimes within serum albumins for chiral recognition. The method is fast and simple, as it requires just one measurement per sample to provide accurate results. It is highly sensitive and is appropriate for analysis of minute ( $\mu \mathrm{g})$ amounts. As further advantages, it avoids substrate derivatization as well as chromatographic separation and does not depend on the specific rotation on the target compound. All together, the above reasons make this LFP-based approach a very complementary tool to the existing techniques. 


\section{Experimental Section}

Experimental details for a typical determination of the enantiomeric composition of a given sample, i. e. the (S)-FBPMe/(R)-FBPMe/HSA 0.5/0.5/1 ratio follows.

To prepare the solution containing a mixture of $(S)$ - and (R)-FBPMe and HSA in 0.5:0.5:1 molar ratio we proceeded as follows: to $10 \mathrm{~mL}$ of a $1.25 \cdot 10^{-5} \mathrm{M}$ solution of (S)-FBPMe, $10 \mathrm{~mL}$ of $1.25 \cdot 10^{-5} \mathrm{M}$ of (R)-FBPMe in PBS and $2.48 \mu \mathrm{L}$ of HSA $2 \cdot 10^{-3} \mathrm{M}$ in PBS were added. The resulting solution $(4 \mathrm{~mL})$ was placed in a quartz cuvette and submitted to LFP (10 shots for monitoring at $360 \mathrm{~nm}$ ). The laser flash photolysis experiment was performed by using a Q-switched Nd:YAG laser (Quantel Brilliant, 266 $\mathrm{nm}, 10 \mathrm{~mJ}$ per pulse, $5 \mathrm{~ns}$ fwhm) coupled to a mLFP-111 Luzchem miniaturized equipment. The absorbance of FBPMe was found to be $c a .0 .2$ at the laser wavelength, corresponding to a concentration of $2.5 \cdot 10^{-5} \mathrm{M}$. The experiment was carried out in PBS $(\mathrm{pH}=7.4,0.01 \mathrm{M})$ at room temperature $\left(22^{\circ} \mathrm{C}\right)$ and under air atmosphere.

Under the employed experimental conditions, upon $266 \mathrm{~nm}$ excitation, FBPMe absorbs ca $17 \%$ of the incident ligth (see Figure S14 in the Supporting Information). However, this is enough to produce a good quality signal in LFP. Fortunately, control experiment show that direct absorption by the protein does not lead to any interfering transient absorption.

Emission of the FBPMe/HSA complex perfectly matched with the calculation for the independent emission of the two components, taking into account the relative absorbance. This allows to rule out singlet-singlet energy transfer between FBPMe and Trp (see Figure S15 in the Supporting Information).

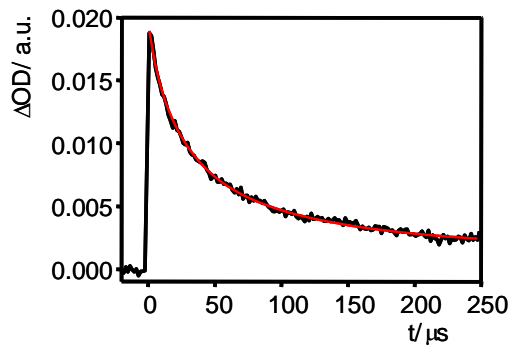

Figure 3. Laser flash photolysis $\left(\lambda_{\text {exc }}=266 \mathrm{~nm}\right)$ of $(S)-\mathrm{FBPMe} /(R)-\mathrm{FBPMe} / \mathrm{HSA}$ at molar ratio 0.5:0.5:1. The black trace is the decay obtained at $360 \mathrm{~nm}$, while the red one corresponds to the exponential fitting (eq. 1) of the decay. The procedure followed for experimental determination of the enantiomeric composition is explained in the text.

To obtain an accurate decay trace, this experiment was repeated at least three times with fresh sample; triplet lifetimes and fittings of the decay traces were coincident within the experimental error margins (Figure 3).

The decay trace was fitted with Eq 1. Taking into account that $\tau_{I}^{\mathrm{S}}=31.5 \mu \mathrm{s}, \tau_{\mathrm{II}^{\mathrm{S}}}^{\mathrm{S}}=4.1 \mu \mathrm{s}$, $\tau_{\mathrm{I}}^{\mathrm{R}}=157.6 \mu \mathrm{s}, \tau_{\mathrm{II}}^{\mathrm{R}}=16.6 \mu \mathrm{s}$, and that the relationship between the coefficients (previously obtained at $1: 1$ drug/SA molar ratio) is $\mathrm{A}_{I}{ }^{\mathrm{S}} / \mathrm{A}_{I I} \mathrm{~S}=70 / 30$ and $\mathrm{A}_{I} \mathrm{R}^{\mathrm{R}} / \mathrm{A}_{I I}{ }^{\mathrm{R}}=$ 68/32, application of Eq 1 leads to: $A_{I}{ }^{S}=0.00628 \pm 0.00017, A_{I I}{ }^{S}=0.00269 \pm 0.00017$, $\mathrm{A}_{\mathrm{I}}^{\mathrm{R}}=0.00608 \pm 0.00014, \mathrm{~A}_{\mathrm{II}}^{\mathrm{R}}=0.00286 \pm 0.00014$.

Now, the percentage of the (S)- enantiomer can be calculated using [Eq. (2)]

$$
\% S=\frac{\left(A_{1}^{S}+A_{\|}^{S}\right) \times 100}{A_{1}^{S}+A_{\|}^{S}+A_{1}^{R}+A_{\|}^{R}}
$$

Operating in this way, the percentage of (S)-FBPMe was found to be $50 \%$.

\section{Acknowledgements}

Financial support from the MEC (Grant CTQ2007-67010 and predoctoral fellowship to C.J.B. and I. V), from the Carlos III Institute of Health (Grant RIRAAF, RETICS program) and from the Generalitat Valenciana (Prometeo Program) is gratefully acknowledged.
[1] M. G. Finn, Chirality 2002, 14, 534-540.

[2] H. Aboul-Enein and I. Wainer, The Impact of Stereochemistry on Drug Development and Use, John Wiley \& Sons, Inc., New York, USA, 1997; Norbert, N. N., Franco, P., Lindler, W. J. Chromatogr. A 2001, 906, 3-33.

[3] a) W.H Pirkle, J. M. Finn, J. Org. Chem. 1981, 46, 2935-2938; b) Y. Okamoto, E. Yashima, Angew. Chem. Int. Ed. 1998, 37, 1026.1043.

[4] a) T. J. Edkins, D. R. Bobbit, Anal. Chem. 2001, 3, 488a; b) M. Tsukamoto, H. B. Kagan, Adv. Synt. Catal. 2002, 344, 453-463.

[5] a) J. Guo, J. Wu, G. Siuzdak, M. G. Finn, Angew. Chem., Int. Ed. 1999, 38 1755-1758; b) M. T. Reetz, M. H Becker, H.-W. Klein, D. Stöckigt, Angew. Chem., Int. Ed.. 1999, 38, 1758-1761; c) C. Markert, A. Pfaltz, Angew. Chem., Int. Ed. 2004, 43, 2498-2500.

[6] a) M. T Reetz,. K. M. Kuhling, A. D Deege, H. Hinrichs, D. Belder, Angew. Chem., Int. Ed. 2000, 39, 3891-3893; b) Abato, P.; Seto, C. T. J. Am. Chem. Soc 2001, 123, 9206-9207; c) R. A. van Delden, B. L. Feringa, Angew. Chem., Int. Ed. 2001, 40, 3198-3200; d) F. Taran, C. Gauchet, B. Mohar, S. Meunier, A Valleix, P. Y Renard, C. Créminon, J. Grassi, A. Wagner, C. Mioskowski, Angew. Chem., Int. Ed. 2002, 41, 124-127; e) L. Li, B. Butikofer, B. Witholt, Angew. Chem., Int. Ed. 2004, 43, 1698-1702; f) R. Eelkema, R. A. van Delden, B. L. Feringa, Angew. Chem., Int. Ed. 2004, 43, 5013-5016; g) S. Dey, K. R. Karukurichi, W. Shen, D. B Berkowitz, J. Am. Chem. Soc. 2005, 127, 86108611; h) Mei, X.; Wolf, C. J. Am. Chem. Soc. 2006, 128, 13326-13327.

[7] M. T. Reetz, M. H. Becker, K. M. Kuhling, A. Holtzwarth, Angew. Chem., Int. Ed. 1998, 37, 2647-2650.

[8] K. Ding, A. Ishii, K. Mikami, Angew. Chem., Int. Ed. 1999, 38, 497- 501.

[9] a) M. T. Reetz, K. M. Kuhling, A. Deege, H. Hinrichs, D. Belder, Angew. Chem., Int. Ed. 2000, 97, 3891-3893; b) L. G. Blomberg, H. Wan, Electrophoresis 2000 21, 1940-1952.

[10] a) C. S. Yannoni, Acc. Chem. Res, 1982, 15, 201-208; b) P. Tekely, C Gardiennet, M. J. Potrzebowski, A. Sebald, D. Reichert, Z. Luz, J. Chem. Phys. 2002, 116, 7607-7616; c) M. J. Potrzebowski, E. Tadeusiak, K. Misiura, W. Ciesielski, G. Bujacz, P. Tekely, Chem. Eur. J. 2002, 8, 5007-5011;d) M. A Evans, J. P. Morken, J. Am. Chem. Soc. 2002, 124, 9020-9021.

[11] a) T. D. James, K. R. A. S. Sandanayake, S. Shinkai, Nature 1995, 374, 345-347. b) G. T. Copeland, S. J. Miller, J. Am. Chem. Soc. 1999, 121, 4306-4307; c) G. Beer, K. Rurack, J. Daub, J. Chem. Soc., Chem. Commun. 2001, 1138-1139; d) J. Zhao,T. M. Fyles, T. D. James, Angew. Chem., Int. Ed. 2004, 43, 3461-3464; e) L. Pu Chem. Rev. 2004, 104, 1687-1716; f) Z.-B. Li, J. Lin, Y.-C. Qin, L. Pu, Org. Lett. 2005, 7, 3441-3444.

[12] a) P. Abato, C. T. Seto, J. Am. Chem. Soc. 2001, 123, 9206-9207; b) F. Taran, C. Gauchet, B. Mohar, S. Meunier, A. Valleix, P. Y. Renard, C. Creminon, J. Grassi, A. Wagner, C. Mioskowski, Angew. Chem., Int. Ed. 2002, 41, 124-127; c) M. Matsushita, K. Yoshida, N. Yamamoto, P. Wirsching, R. A. Lerner, K. D. Janda, Angew. Chem., Int. Ed. 2003, 42, 5984-5987; d) A. Hamberg, S. Lundgren, M. Penhoat, C. Moberg, K. Hult, J. Am. Chem. Soc. 2006, 128, 22342235.

[13] a) K. W. Busch, I. M. Swamidoss, S. O. Fakayode, M. A. Busch, J. Am. Chem. Soc. 2003, 125, 1690-1691; b) S. O. Fakayode, M. A. Busch, D. J. Bellert, K. W. Busch, Analyst 2005, 130, 233-241; c) K. W. Busch, I. M. Swamidoss, S. O. Fakayode, M. A. Busch, J. Am. Chem. Soc. 2003, 125, 1690-1691.

[14] a) V. K. Challa, B. Apinya, C. S. Ho, Chem. Commun. 2001, 297-298; b) Y. Abe, S. Yasuoka, T. Shoji, S. Sugata, K. Hattori, K. Iwata, H. Suzuki, Anal. Sci. 2002, 18, 823-825; c) J. Hamblin, N. Abboyi, M. P. Lowe, Chem. Commun. 2005, 657-659; d) S. S. Singh, J. Mehta, J. Chromatogr. B. 2006, 834, 108-116; e) H. Hödl, J. Koidl, M. G. Schmid, G. Gübitz, Electrophoresis 2006, 27, 47554762; f) M. A. Martínez-Gómez, S. Sagrado, R. M. Villanueva-Camañas, M. J Medina-Hernández,. Anal. Chim. Acta. 2007, 582, 223-228.

[15] a) M. C. Jiménez, I.Vayá, M. A. Miranda, J. Am. Chem. Soc. 2005, 127, 10134 10135; b) I. Vayá, I.; C. J. Bueno, M. C. Jiménez, M. A. Miranda, ChemMedChem. 2006, 1, 1015-1020.

[16] C. Bohne, M. Barra, R. Boch, E. B. Abuin, J. C. Scaiano, J. Photochem. Photobiol. A: Chem., 1992, 65, 249-265.

[17] M. C. Jiménez, M. A. Miranda, R. Tormos, I. Vayá, Photochem. Photobiol. Sci. 2004, 3, 1038-1041.

[18] G. Sudlow, D. J. Birkett, D. N. Wade, Mol. Pharmacol. 1976, 12, 1052-1061.

[19] T. Peters, All About Albumins: Biochemistry Genetics and Medical Applications, Academic Press, San Diego, 1995 